\title{
Overhaul of the reducing ability of Breslow-type derivatives and implications for carbene-catalyzed radical reactions.
}

\author{
Ludivine Delfau, ${ }^{[\mathrm{a}]}$ Samantha Nichilo, ${ }^{[\mathrm{a}]}$ Florian Molton, ${ }^{[\mathrm{a}]}$ Julie Broggi, ${ }^{[\mathrm{b}]}$ \\ Eder Tomás-Mendivil ${ }^{*[a]}$ and David Martin ${ }^{\star[a]}$

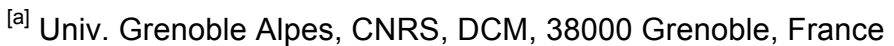 \\ ${ }^{[b]}$ Aix Marseille Univ., CNRS, Institut de Chimie Radicalaire (ICR), 27 Bd Jean Moulin, 13385, Marseille, France
}

\begin{abstract}
We report the synthesis of acyl azolium salts stemming from thiazolylidenes $\mathbf{C}_{\mathrm{NS}}$, triazolylidenes $\mathbf{C}_{\mathrm{TN}}$, mesoionic carbenes $\mathbf{C}_{\mathrm{MIC}}$ and the generation of their corresponding radicals and enolates, covering about 60 Breslow-type derivatives. This study highlights the role of additives in the redox behavior of these compounds and unveils several critical misconceptions about radical transformations of aldehyde derivatives under N-heterocyclic carbene catalysis. In particular, the reducing ability of enolates has been dramatically underestimated in the case of biomimetic $\mathbf{C}_{\mathrm{NS}}$. In contrast with previous electrochemical studies, we show that these catalytic intermediates can transfer electrons to iodobenzene within minutes at room temperature. Enols derived from $\mathbf{C}_{\text {MIC }}$ are not the previously claimed super electron donors, although enolate derivatives of $\mathbf{C}_{\mathbf{N S}}$ and $\mathbf{C}_{\mathbf{M I C}}$ are powerful reducing agents.
\end{abstract}

\section{Introduction}

The design of novel radical transformations of aldehydes has become the new frontier in the competitive field of $\mathrm{N}$-Heterocyclic Carbene $(\mathrm{NHC})$ organocatalysis ${ }^{[1]}$ In 2014, following a seminal report of Studer et al., ${ }^{[2]}$ the teams of Chi and Rovis separately showed that mild oxidants could trigger radical transformations of aldehyde derivatives under $\mathrm{NHC}$-catalysis. ${ }^{[3]}$ There ensued an ever-increasing number of reports proposing formal formation and trapping of radicals. ${ }^{[4-8]}$

The first step of the catalytic cycle is well-accepted: NHC catalysts react with aldehyde derivatives to yield enaminols $\mathbf{A} \cdot \mathbf{H}$, so called Breslow intermediates. ${ }^{[9-11]}$ Early hypotheses involved formation of radicals through a single electron transfer (SET) from $\mathbf{A} \cdot \mathbf{H}$ to an oxidative substrate $\mathbf{S}$. In 2019 , in collaboration with the Bertrand group, we demonstrated that even electron-enriched models for $\mathbf{A} \bullet \mathbf{H}$ were too weak reductants and proposed the corresponding enolates $\mathbf{A}^{-}$as more suitable reducing agents (Figure 1-a). ${ }^{[12]}$ Note that earlier catalytic studies considered triazolylidene $\left(\mathbf{C}_{\mathrm{TN}}\right)$ derivatives, for whom no electrochemical data were available. Later works established thiazolylidenes $\left(\mathbf{C}_{\mathbf{N S}}\right)$ as catalysts of choice. Cyclic voltammetry studies of the corresponding enolates $\mathbf{A}^{-}$were published by Fukuzumi et al. in the late $1990 \mathrm{~s},{ }^{[13]}$ with oxidation potentials as low as $-0.9 \mathrm{~V}$ versus SCE (Figure 1-b). Therefore, the postulated SET from enolates to mild oxidants $\left(E_{\text {red }}>\right.$ - 
$0.9 \mathrm{~V})^{[14]}$ accounted for the activation of most substrates at the time, such as nitroaryls, nitrobenzylbromides, nitrostyrenes, nitrosulfonic carbamates, polyhalides or Katrinski's pyridinium salts.

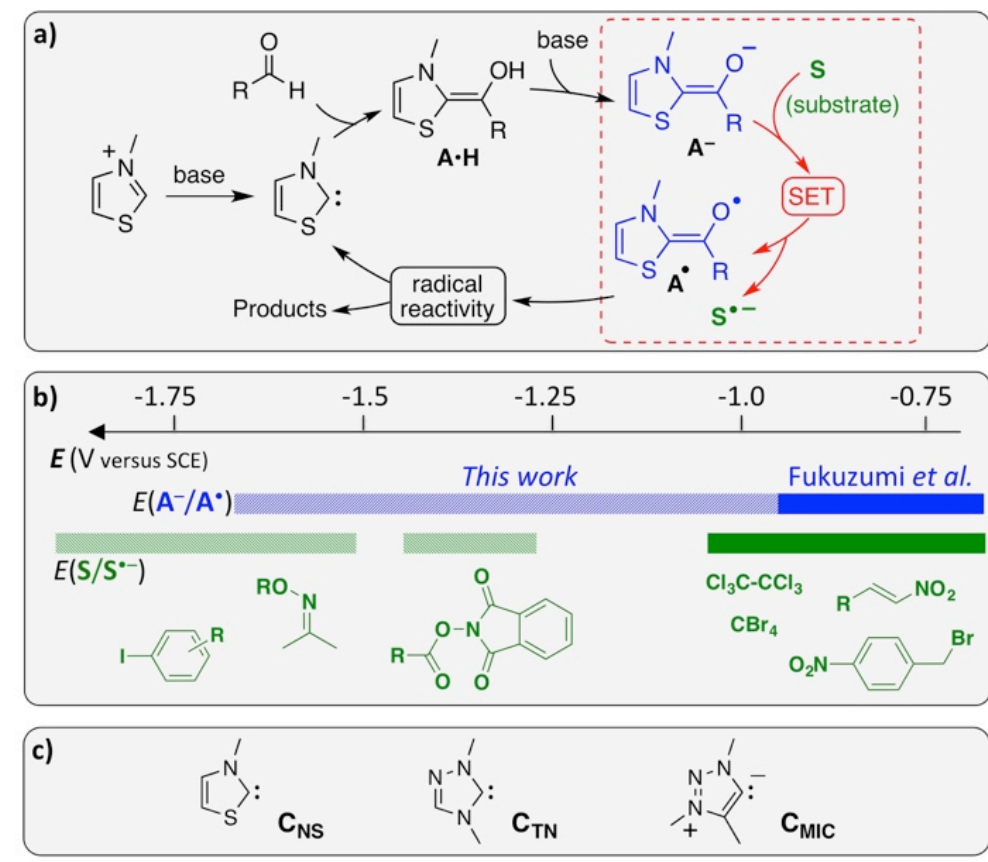

Figure 1: (a) Schematic catalytic cycle for NHC-catalyzed radical transformation of aldehydes.

Proposed key Single Electron Transfer (SET) between enolate $\mathbf{A}^{-}$and substrate $\mathbf{S}$ is highlighted in red. (b) Range of potentials for the oxidation of $\mathbf{A}^{-}$according to Fukuzumi et al. (blue) and for the reduction of typical substrates or ancillary oxidants (green). (c) Structure of typical NHC catalysts.

However, very recent publications have questioned again this rationale. For instance, the substitution of aldehydes to afford ketones under thiazolylidene $\left(\mathbf{C}_{\mathrm{NS}}\right)$ catalysis was achieved with $\mathrm{N}$-(acyloxy)phthalimides ${ }^{[5]}$ or oxime ethers,${ }^{[6]}$ which are known sources of alkyl radicals upon reduction below $-1.4 \mathrm{~V}^{[15]}$ and $-1.6 \mathrm{~V},{ }^{[16]}$ respectively. Even more, the groups of Ohmiya ${ }^{[17]}$ and Bertrand with Yan $^{[18]}$ independently reported the activation of challenging iodoaryls in presence of styrenes and aldehydes, with thiazolylidenes $\left(\mathbf{C}_{\mathrm{NS}}\right)$ or mesoionic carbenes $\left(\mathbf{C}_{\text {MIC }}\right)$, respectively. For $\mathbf{C}_{\text {MIC }}$ catalysts, the authors proposed that the mesoionic structure results in an electron-rich enaminol $\mathbf{A} \cdot \mathbf{H}$ with an oxidation potential as low as $-1.93 \mathrm{~V}$. Yet, this unusual value was supported by ambiguous electrochemical data (see further below). For another instance, Du et al. proposed that $\mathrm{Mg}(\mathrm{II})$ cations coordinate and activate oxime esters, thus allowing to patch up the potential gap with Breslow enolates. ${ }^{[6]}$ Still, other protocols do not similarly involve hard oxophilic Lewis acids. The case of the reduction of iodoaryls in presence of thiazolylidene catalysts is especially spectacular, as reduction potentials of substrate ${ }^{[19]}$ can be up to $1.5 \mathrm{~V}$ lower than the reported values for the oxidation potential of Breslow enolates. ${ }^{[13]}$

The inadequacy between the few available electrochemical data and the overachievement of methodological approaches had clearly reached a tipping point. In order to decipher this riddle and to guide the design of future NHC-catalyzed radical reactions, we reinvestigated the electrochemistry of Breslow-type derivatives. 
Herein, we provide for a renewed picture of the redox properties of these compounds. Our data unveil critical misconceptions in the field. In particular, we show that the reducing ability of enolates $A^{-}$has been dramatically underestimated in the case of biomimetic thiazolylidenes.

\section{Results and Discussion}

The few available electrochemical data on $\mathbf{C}_{\mathrm{NS}}$-based derivatives from Fukuzumli et al. ${ }^{[13]}$ fitted in the picture drawn from later studies on other NHC-acyl adducts. ${ }^{[12,20]}$ Indeed, reported cyclic voltammograms of enolates $\mathbf{A}^{-}$featured two successive reversible oxidation waves. ${ }^{[13]}$ One-electron oxidations afforded very persistent radicals $\mathbf{A}^{*}$, which were characterized by EPR. However, the authors generated enolates from the NHC precursor, 2 equivalents of base (DBU: 1,8diazabicyclo[5.4.0]undec-7-ene) and excess of aldehyde (Scheme 1-a). A possible analytic bias may arise from the complexity of these crude mixtures. Thus, we underwent the synthesis of a series of acyl azolium salts $\mathbf{A}^{+}$, which are well-defined isolable precursors for enolates $\mathbf{A}^{-}$.

Fukuzumi's seminal works focused on $\mathrm{N}$-benzyl substituted compounds, which are close structural analogues of the thiamine derivatives. The corresponding acyl thiazoliums, such as $1 \mathbf{a}^{+}$and $\mathbf{1 b}^{+}$(Scheme 1-b), cannot be obtained by addition of thiazolylidenes $\mathbf{C}_{\mathrm{NS}}$ to acyl chlorides, which would be the usual straightforward synthesis of the corresponding acyl azolium salts with other NHCs. ${ }^{[12,20]}$ Indeed, this method is limited to the rare persistent carbenes $\mathbf{C}_{\mathbf{N s}}{ }^{[21]}$ with a bulky 2,6diisopropylphenyl (Dipp) $N$-substituent (Scheme 1-c). Furthermore, we found that alkylation of weakly nucleophilic acyl thiazoles ${ }^{[22]}$ was only satisfying for the introduction of an $\mathrm{N}$-methyl substituent with methyltriflate (Scheme 1-d), but inefficient and/or sluggish with benzyltriflate or benzylhalides, even in harsh conditions. We looked for a more robust methodology for the synthesis of a broad family of acyl thiazolium salts relying on an in situ carbene trapping strategy. The use of sodium hydride (as a non-nucleophilic base) in acetonitrile allowed for the clean formation of the desired salts starting from the corresponding thiazolium salt ${ }^{[5 b, 21 b, 23]}$ and readily accessible acyl chlorides (Scheme 1-e). An excess of base and acyl chloride allowed for reaching full conversion, even in presence of moisture. Indeed, hydrolysis led to the side formation of acyl anhydrides, which were easily removed by extraction with diethylether. Note that we have not observed any side-product stemming from the reaction of $\mathrm{NaH}$ with the solvent. ${ }^{[24]}$ Importantly, purifications involve aqueous work-ups, indicating that acyl thiazolium salts are not as sensitive to moisture as previously suggested. ${ }^{\left[{ }^{[f]}\right.}$ We also applied this procedure to the synthesis

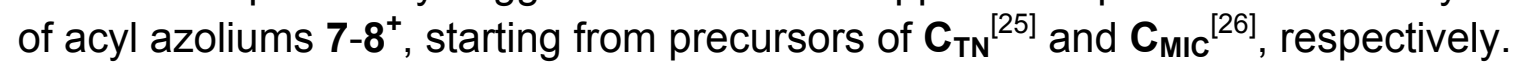

Cyclic voltammograms of $\mathrm{N}$-benzyl substituted acyl thiazoliums $\mathbf{1 a}^{+}$and $\mathbf{1 b}^{+}$are shown in black in Figure 2. They feature a first reversible reduction wave at $-0.58 \mathrm{~V}$ and $-0.54 \mathrm{~V}$, respectively. Note that these are Fukuzumi's reported value for the second reversible oxidation of $1 \mathrm{a}^{-}$. We performed quantitative reduction at $-0.7 \mathrm{~V}$. Coulometry (stoichiometry of one coulomb per mole of acyl thiazolium) and 
cyclovoltammograms of the resulting solution (similar to acyl thiazoliums) confirmed the formation of persistent radicals $1 \mathrm{a}^{\circ}$ and $1 \mathbf{b}^{\circ}$. The isotropic $X$-band room temperature EPR spectra of the solution was identical to previous observations in complex mixtures ${ }^{[13,23 a]}$. The assignment was further confirmed by the prediction of similar values for hyperfine coupling constants ${ }^{[27]}$ at the $M 06 / 6-311++g(d, p)$ level of theory with the Polarizing Continuum Model (PCM) for acetonitrile as solvent ${ }^{[28]}$ (see supporting information for details).

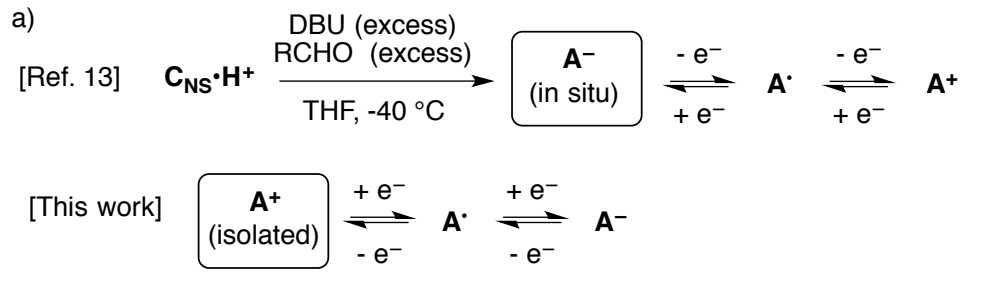

b)

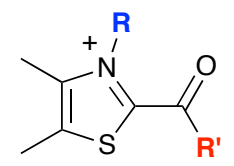<smiles></smiles>

1a+: $\mathrm{R}=\mathrm{PhCH}_{2} ; \mathrm{R}^{\prime}=\mathrm{Ph}$

1b+: $\mathrm{R}=\mathrm{PhCH}_{2} ; \mathrm{R}^{\prime}=2-\mathrm{Me}\left(\mathrm{C}_{6} \mathrm{H}_{4}\right)$

2a+: R = Dipp $\quad ; R^{\prime}=P h$

2b+: R = Dipp $\quad ; R^{\prime}=2-\operatorname{Me}\left(\mathrm{C}_{6} \mathrm{H}_{4}\right)$

2c': $R=$ Dipp $; R^{\prime}=t B u$

2d+: R = Dipp $; \mathrm{R}^{\prime}=4-\mathrm{Cl}\left(\mathrm{C}_{6} \mathrm{H}_{4}\right)$

2e+: $\mathrm{R}=$ Dipp $; \mathrm{R}^{\prime}=4-\mathrm{Me}\left(\mathrm{C}_{6} \mathrm{H}_{4}\right)$

2f+: $\mathrm{R}=\mathrm{Dipp} \quad ; \mathrm{R}^{\prime}=4-\mathrm{OMe}\left(\mathrm{C}_{6} \mathrm{H}_{4}\right)$

3a+: $\mathrm{R}=$ Mes $; \mathrm{R}^{\prime}=\mathrm{Ph}$

4a+: $\mathrm{R}=\mathrm{Ph} \quad ; \mathrm{R}^{\prime}=\mathrm{Ph}$

5a+: $\mathrm{R}=\mathrm{Me} \quad ; \mathrm{R}^{\prime}=\mathrm{Ph}$

$6 \mathbf{a}^{+}: \mathrm{R}=t \mathrm{BuCH}_{2} \quad ; \mathrm{R}^{\prime}=\mathrm{Ph}$

6b': $\mathrm{R}=t \mathrm{BBCH}_{2} \quad ; \mathrm{R}^{\prime}=2-\mathrm{Me}\left(\mathrm{C}_{6} \mathrm{H}_{4}\right)$

6c': $\mathrm{R}=\mathrm{tBuCH}_{2} \quad ; \mathrm{R}^{\prime}=t B u$<smiles>O=C(c1ccccc1)c1sc2c([n+]1[Pb])CCCCC2</smiles><smiles>O=C(c1ccccc1)c1sc2c([n+]1[Pb])CCC2</smiles>

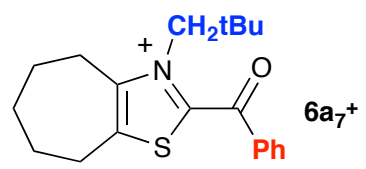<smiles>O=C(c1ccccc1)c1n(-c2ccccc2)nc(-c2ccccc2)[n+]1-c1ccccc1</smiles><smiles>O=C([Pb])c1c([Pb])nnc2[n+]1CCC2</smiles><smiles></smiles>

c)<smiles>[R]C1=C([Tl])N([O+])C=[SH]1</smiles><smiles>O=Cc1ccccc1</smiles>

$$
\text { Dipp: 2,6-iPr } 2\left(\mathrm{C}_{6} \mathrm{H}_{3}\right)
$$

Mes: $2,4,6-\mathrm{Me}_{3}\left(\mathrm{C}_{6} \mathrm{H}_{2}\right)$

d)<smiles></smiles><smiles>CC=C(P)Cl</smiles>

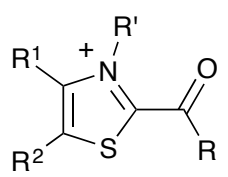

e)<smiles>[R7]c1sc[n+]([Tl])c1[Tl]</smiles><smiles>CCCC(C)NC(=O)Cl</smiles>

Scheme 1: (a) generation of enolates $\mathbf{A}^{-}$and in situ electrochemical study according to ref. 13; (b) Structure of acyl azoliums $1^{+}-8^{+}$; synthesis of acyl thiazolium by: (c) acylation of persistent carbenes, (d) alkylation of an acyl thiazole or (e) in situ trapping of transient carbenes with acyl chlorides. 
In contrast, the reduction of $1^{\circ}$ to form $\mathbf{1}^{-}$occurred at a significantly lower potential $\left(E^{\circ}\right.$ for $\left.1 \mathbf{a}^{*} / \mathbf{1} \mathbf{a}^{*}:-1.3 \mathrm{~V} ; \mathbf{1} \mathbf{b}^{*} / \mathbf{1}^{-}:-1.4 \mathrm{~V}\right)$ than the previously reported reversible oxidation of $\mathbf{1}^{-}$to afford $\mathbf{1}^{*}\left(\mathbf{a}^{-} / 1 \mathbf{a}^{*}:-0.79 \mathrm{~V} ; \mathbf{1 b}^{-} / \mathbf{1}^{*}:-0.98 \mathrm{~V}\right)$. In order to mimic the conditions of previous studies of $1 \mathrm{a}^{-}$, we added two equivalents of $\mathrm{DBU}^{\mathrm{H}} \cdot \mathrm{HPF}_{6}$ to the solution containing the acyl thiazoliums. As a result, the $\mathbf{1}^{1 / \mathbf{1}^{-}}$wave was shifted (Figure 2, in red) and ultimately matched the previously reported electrochemical data for $\mathbf{1} \mathbf{b}^{\mathbf{b}} / \mathbf{1} \mathbf{b}^{\mathbf{}}$ (in the case of $1 a^{-} / 1 a^{\circ}$ we attributed the difference to the fact that former data were recorded at $\left.-40^{\circ} \mathrm{C}\right)$.

a)
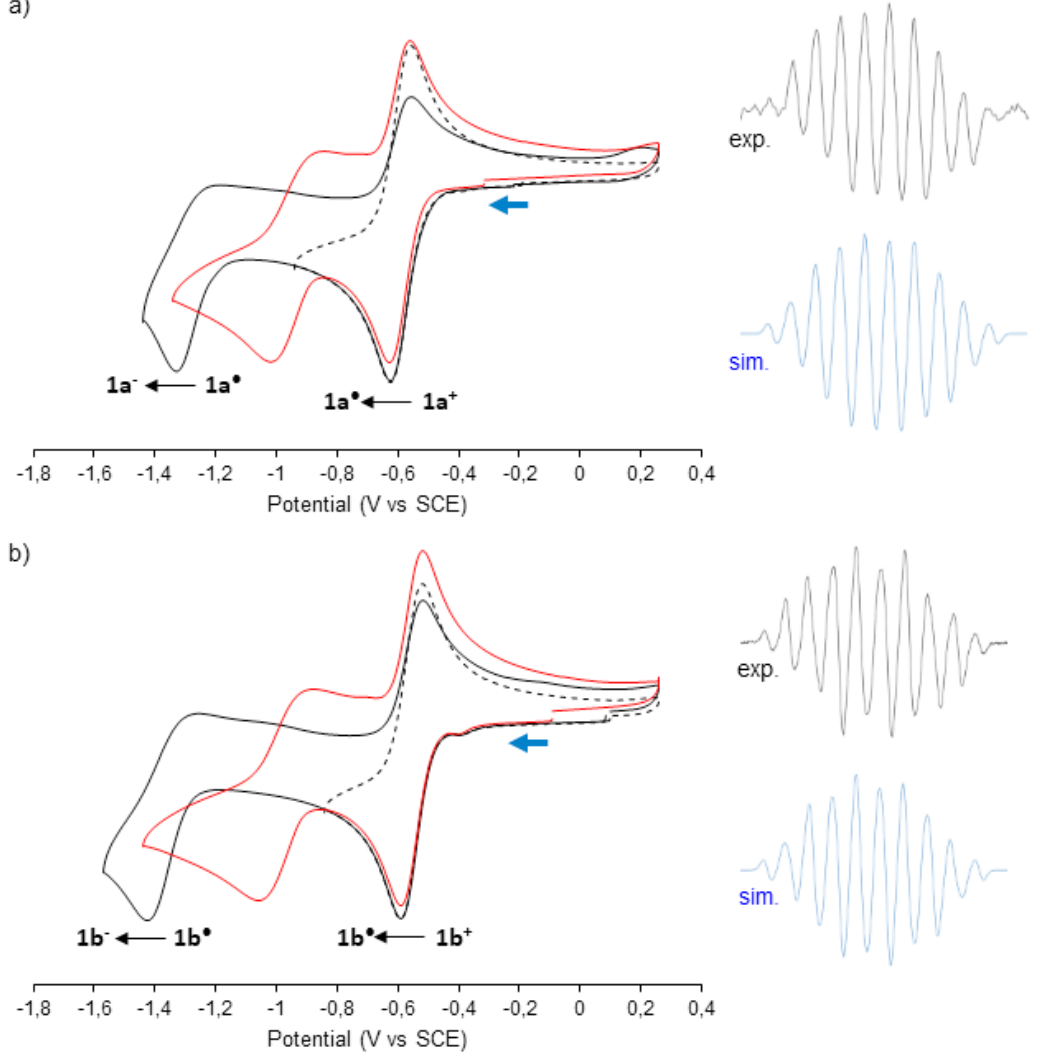

Figure 2: left (in black), cyclic voltammetry of $1 \mathrm{mM}^{1 a^{+}}(\mathrm{a})$ or $\mathbf{1 b}^{+}(\mathrm{b})$ in acetonitrile with $0.1 \mathrm{M}$ $n B$ BNPF6 electrolyte at $100 \mathrm{mV} / \mathrm{s}$ rate; right, corresponding experimental and simulated isotropic $\mathrm{X}$ band EPR spectra of radicals $1 \mathrm{a}^{\mathbf{}}$ and $\mathbf{1 b}^{\mathbf{*}}$. Cyclic voltammograms in red were obtained after addition of 2 equivalents of $\mathrm{DBU} \cdot \mathrm{HPF}_{6}$ to electrolyte solutions of $\mathbf{1} \mathbf{a}-\mathbf{b}^{+}$.

We observed a similar effect upon addition of DBU $\cdot \mathrm{HPF}_{6}$ to a solution of $\mathbf{2 a}^{+}$(Figure $3-a)$. As for $1 a^{+}$, the $2 a^{+} / 2 a^{*}$ wave remained unchanged, indicating that only the enolate form is sensitive to the presence of the additive. Importantly, the formation of Breslow enaminols $\mathbf{A} \cdot \mathbf{H}$ was ruled out. Indeed, these latter compounds are very mild oxidants, with oxidation potentials above $-0.2 \mathrm{~V}^{[29]}$ Addition of stronger acids (triethylamonium or ammonium) resulted in a shifted reduction wave of $\mathbf{2} \mathbf{a}^{\bullet}$ with no back-oxidation below $-0.6 \mathrm{~V}$, which is expected from the protonation of the enolate (Figure 3-a). As a whole, the electrochemical behavior of the system in presence of $\mathrm{DBU} \cdot \mathrm{H}^{+}$suggests a fast and reversible formation of stabilizing hydrogen-bonds with the enolates. ${ }^{[30]}$

We considered that O-coordination of the enolates by Lewis acids should have similar effects. Accordingly, we observed only a small shift upon addition of 
potassium salt to $2 \mathrm{a}^{+}$, but a significant one with the hard oxophilic lithium cation (Figure 3-b). In this latter case, the oxidation of $2 a^{-}$is followed by a chemical transformation. Note that addition of lithium perchlorate to acyl azolium $\mathbf{5 a}^{+}$afforded a clean reversible shifted wave (see Figure 3-c). Several catalytic processes performed better with caesium or potassium over sodium and lithium salts. ${ }^{[5 a, 6 a]}$ Retrospectively, the decrease of the reducing capabilities of enolates $\mathbf{A}^{-}$by hard Lewis acids helps to explain how the nature of counter-cations can be a key parameter in methodological optimizations.
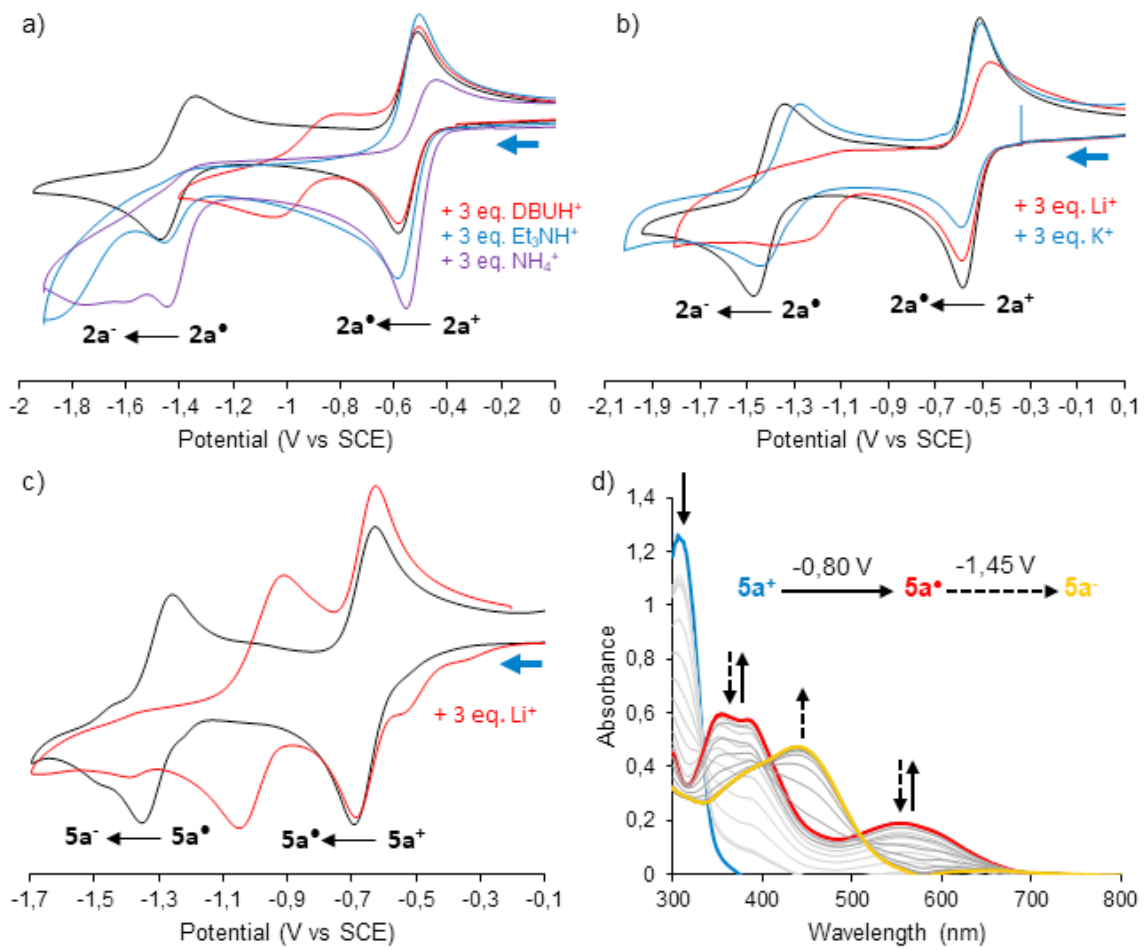

Figure 3: cyclic voltammetry in acetonitrile with $0.1 \mathrm{M} \mathrm{nBu}_{4} \mathrm{NPF}_{6}$ electrolyte at 100 $\mathrm{mV} / \mathrm{s}$ rate of $1 \mathrm{mM}$ solution of (a) $2 \mathrm{a}^{+}$, (b) $\mathbf{2} \mathbf{b}^{+}$and (c) $5 \mathbf{a}^{+}$with (color) or without

(black) various additives. (d) UV-vis monitoring of successive quantitative electrolyses of $5 \mathbf{a}^{+}$at $-0.8 \mathrm{~V}$ and $5 \mathbf{a}^{\circ}$ at $-1.45 \mathrm{~V}$.

All details for the electrochemical studies of our whole set of acyl azolium salts $\mathbf{A}^{+}$ and generated reduction products are reported in the Supplementary Information. Note that - unsurprisingly - the results were insensitive to the nature of the counter anion in the acyl azolium salt $\left(\mathrm{PF}_{6}^{-}, \mathrm{ClO}_{4}^{-}, \mathrm{Cl}^{-}\right)$. The corresponding radicals $\mathrm{A}^{\circ}$ were generated by quantitative electrolysis and characterized by EPR. Most are very persistent under inert atmosphere, as expected from related capto-dative radicals. ${ }^{[20]}$ The hyperfine structure of isotropic spectra essentially depends on the NHC scaffold and DFT calculations confirmed the absence of spin delocalization on the R' substituent of the carbonyl moieties. Importantly, we followed the quantitative electrolysis of $\mathbf{A}^{+}$to afford $\mathbf{A}^{-}$and $\mathbf{A}^{-}$with in situ UV-vis monitoring, providing $\mathbf{U V}$-vis spectra for more than 60 Breslow-type derivatives. We believe that these data are 
not only of interest for future works, including the design and study of NHC-catalyzed photo-redox processes, but also for retrospective analyses of the literature. For instance, the UV-vis signature of $5 \mathbf{a}^{\circ}$ (see Figure $3-d$ ) corresponds to the enamine degradation product formed upon reaction of in situ generated Breslow type enamines with flavin analogues in a previously reported biochemical study. ${ }^{[31]}$

Key redox potentials are summarized in Table 1. All cyclic voltammograms of acyl thiazoliums $1-6^{+}$feature a reversible first reduction wave at $E^{\circ}\left(\mathbf{A}^{\circ} / \mathbf{A}^{+}\right)=-0.5--0.7 \mathrm{~V}$. In spite of few partially irreversible second reduction waves (scan rates up to $1 \mathrm{~V} / \mathrm{s}$ ), fair estimates for all $E^{\circ}\left(\mathbf{A}^{-} / \mathbf{A}^{*}\right)$ could also be obtained. For a given $\mathbf{C}_{\mathrm{NS}}$ backbone, the reductive ability of $\mathbf{A}^{-}$correlates with the electronic properties of the carbonyl substituent R' (2a-2f and 6a-6c). For a given carbonyl moiety $\left(R^{\prime}=P h, 1 a-6 a\right)$ the most reductive enolate is $\mathbf{2} \mathbf{a}^{-}$, featuring a Dipp $N$-substituent. Interestingly, systems with a $N$-neopentyl group (6a and $\mathbf{6} \mathbf{a}_{\mathbf{7}}$ ) are not especially strong electron donors. Thus, their superior ability to catalyze radical coupling with aliphatic aldehydes ${ }^{[5 b]}$ may be better explained by their higher nucleophilicity. Introduction of a fused ring in the $\mathbf{C}_{\mathrm{Ns}}$ backbone does not significantly change the redox potentials (2a vs $\mathbf{2} \mathbf{a}_{5}, \mathbf{2} \mathbf{a}_{6}, \mathbf{2} \mathbf{a}_{7}$ and $\mathbf{6 a}$ vs $6 \mathbf{a}_{7}$ ). However, $2 \mathbf{a}_{5}{ }^{+}$stands out in the series, with a partially irreversible second reduction wave. The low chemical stability of enolate $2 \mathbf{a}_{5}{ }^{-}$may explain why the corresponding $\mathbf{C}_{\mathbf{N S}} \mathrm{NHC}$ is usually a mediocre catalyst, whereas related models with a fused 6- or 7-membered ring are excellent.

Table $1.1^{\text {st }}$ and $2^{\text {nd }}$ reduction potentials of acyl azoliums $1 \mathbf{a}^{+}-8 \mathbf{a}^{+}\left(E_{1 / 2}\right.$ in $\mathrm{V}$ versus SCE). ${ }^{[\mathrm{a}}$

\begin{tabular}{|c|c|c|c|c|c|c|}
\hline $1 a^{+}$ & $1 b^{+}$ & $2 a^{+}$ & $2 a_{5}^{+}$ & $2 a_{6}^{+}$ & $2 a_{7}^{+}$ & $2 b^{+}$ \\
\hline-0.58 & -0.54 & -0.54 & -0.50 & -0.53 & -0.57 & -0.50 \\
\hline$-1.32^{[b]}$ & $-1.41^{[b]}$ & -1.40 & $>-1.43^{[b]}$ & -1.38 & -1.40 & -1.46 \\
\hline $2 c^{+}$ & $2 d^{+}$ & $2 e^{+}$ & $2 f^{+}$ & $3 a^{+}$ & $4 a^{+}$ & $5 a^{+}$ \\
\hline-0.64 & -0.49 & -0.56 & -0.60 & -0.57 & -0.58 & -0.65 \\
\hline$>-1.7^{[\mathrm{b}]}$ & -1.33 & -1.41 & -1.42 & -1.36 & $-1.18^{[b]}$ & -1.29 \\
\hline $6 a^{+}$ & $6 a_{7}^{+}$ & $6 b^{+}$ & $6 c^{+}$ & $7 a^{+}$ & $7 b^{+}$ & $8 a^{+}$ \\
\hline-0.62 & 0.64 & -0.58 & -0.71 & -0.80 & -0.81 & -1.00 \\
\hline-1.32 & -1.34 & -1.40 & $>-1.6^{[\mathrm{b}]}$ & $>-1.8^{[\mathrm{c}]}$ & $>-1.7^{[\mathrm{c}]}$ & -1.87 \\
\hline
\end{tabular}

[a] See supporting information for extra data and details. ${ }^{[b]}$ Partially irreversible EC process, even at 1 V/s scan rate. ${ }^{[c]}$ Short-lived radical form and possible irreversible EC process for the formation of the enolate.

In absence of additive, enolates $\mathbf{A}^{-}$stemming from $\mathbf{C}_{\mathrm{NS}}$ thiazolylidenes are significantly stronger reducing agents than previously believed. The revised values for $E^{\circ}\left(\mathbf{A}^{-} / \mathbf{A}^{\circ}\right)$ easily account for single electron transfers to most substrates of the literature, although the activation of iodoaryls appears as a major exception.

We considered a reported attempt to evidence the reaction of iodobenzene with a $\mathbf{C}_{\mathrm{NS}}$-based enolate (see page S51 in supporting information of ref. 17) The enolate was generated from the NHC precursor in presence of excess of DBU and 
benzaldehyde. No change in the UV-vis spectra was observed upon addition of iodobenzene. Being now aware of the bias of such approach, we first generated $\mathbf{2 a}^{-}$ by electrolysis of $2 a^{+}$. As expected, no reaction occurred when adding iodobenzene in presence of DBU $\cdot \mathrm{H}^{+}$. In contrast, in absence of acid, UV-vis monitoring and EPR indicated the formation of $2 a^{\circ}$ (Figure 4-a). We have not been able to identify the product stemming from the reduction of $\mathrm{Phl}$ and the decay of $\mathrm{Ph}$. Note that this transient radical does not react with persistent $2 a^{\circ}$, in line with the need for methodological approaches to involve styrene as an intermediate trapping agent. The reaction requires few minutes at room temperature, which is too slow to have an impact on the cyclic voltammetry of $\mathbf{2 a}$. Importantly, the $\mathbf{2} \mathbf{a}^{-} / \mathbf{2} \mathbf{a}^{\circ}$ system catalyzes the electrolysis of excess iodobenzene at $-1.5 \mathrm{~V}$ with a modest, but significant, turnover number (Figure 4-b).

Based on these results, one has to wonder whether iodoaryls are really so challenging. lodobenzene exhibits irreversible cyclic voltammograms. Based on half peak reduction potentials, $E^{\circ}$ of $\left(\mathrm{Phl} / \mathrm{Phl} \mathrm{l}^{\circ}\right)$ was estimated at about $-2.2 \mathrm{~V}$ vs SCE. ${ }^{[19]}$ This is only a very rough estimate of the thermodynamic value, since the nature and rate constants of the fast and irreversible processes at the cathode are unknown. Electron donors with higher oxidation potentials are able to perform reduction of $\mathrm{Phl}^{\left[{ }^{[32]}\right.}$ The exothermic transformations of the resulting radicals are often invoked as thermodynamic drives for the ultimate realization of the reaction (the dissociation of $\mathrm{Phl}^{-}$into $\mathrm{Ph}^{\circ}$ and $\mathrm{I}^{-}$in solution is exothermic by itself). However, this does not account for a decreased activation barrier for the single electron transfer, which is likely the rate limiting step in challenging redox NHC-catalysis. A complementary explanation may arise from an alternative mechanism. Indeed, Savéant et al. showed that the SET-dissociative process competes with a concerted cleavage of the carboniodine bond. The latter process has a lower activation barrier and the corresponding $E^{\circ}$ of $\left.(\mathrm{Phl} / \mathrm{Ph})^{\circ}\right)$ is higher than $-2.0 \mathrm{~V}^{[19 b]}$ 

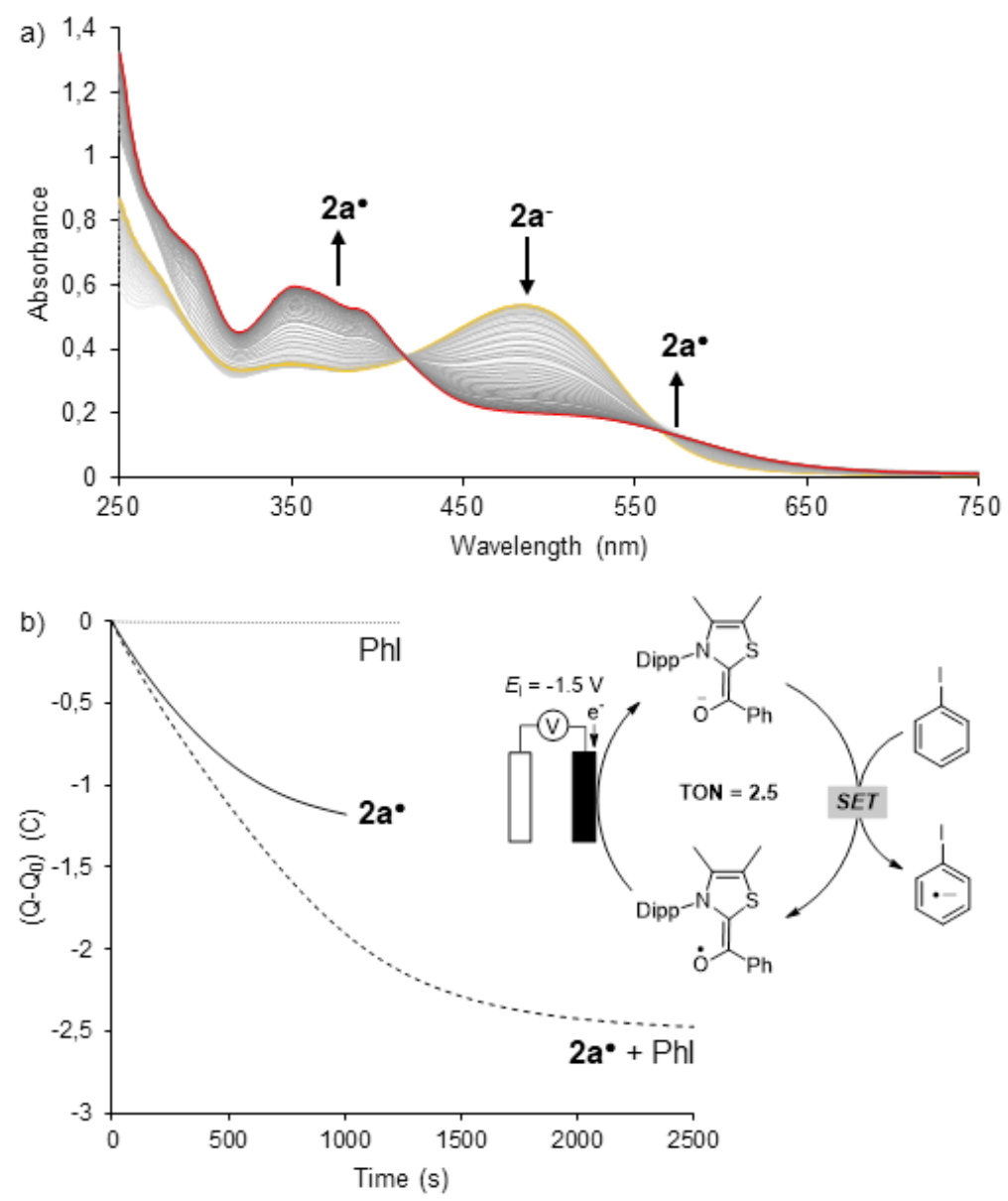

Figure 4: (a) UV-vis monitoring of the reaction of $2 \mathrm{a}^{-}(1 \mathrm{mM})$ with iodobenzene $(2 \mathrm{mM})$. (b) Coulometric monitoring of electrolyses of $2 \mathrm{a}^{\circ}(1 \mathrm{mM})$ and/or $\mathrm{Phl}(20 \mathrm{mM})$ at $-1.5 \mathrm{~V}$ versus SCE.

Next, we considered acyl triazoliums (based on $\mathbf{C}_{\mathrm{TN}} \mathrm{NHCs}$ ), which are efficient catalystsor key intermediates in several oxidative photo-redox transformations. ${ }^{[8]}$ Their reduction potential was estimated at about $-1.3 \mathrm{~V} \cdot{ }^{[8 \mathrm{e}]}$ Again, our data indicate that they are better oxidants, with revised value of about $-0.8 \vee$ for $7 a^{+}$and $7 b^{+}$. Importatnly, reductions do not afford persistent radicals: $7 a^{\circ}$ is short-lived at room temperature and observation of $7 \mathbf{b}^{\circ}$ required the use of an in-house electrochemical device in the EPR cavity (see Supporting Information). Oxidation potentials of the corresponding enolates could be estimated from partially irreversible $2^{\text {nd }}$ reduction waves. They indicate that $\mathbf{C}_{\mathrm{TN}}$-based enolates are strong reducing agents. However, their short lifespan may explain why the use of $\mathbf{C}_{\mathrm{TN}}$ catalysts has been limited to date to the reductive transformation of the least challenging substrates..$^{[3,4 a-h]}$

Finally, we reinvestigated derivatives of mesoionic carbenes $\mathbf{C}_{\text {MIc. }}$. It was recently claimed that corresponding Breslow-type enols, such as $\mathbf{8} \mathbf{a} \cdot \mathbf{H}$, were super electron donors and were able to reduce iodoaryls. ${ }^{[18 a]}$ However, reported cyclic voltammetry experiments were inconsistent. Surprisingly, voltammograms of the proposed reducing agent $\mathbf{8} \mathbf{a} \cdot \mathbf{H}$ featured no oxidation wave. Moreover, $8 \mathbf{a}^{+}, \mathbf{8} \mathbf{a}^{\circ}$ and $\mathbf{8} \mathbf{a} \cdot \mathbf{H}$ afforded unrelated voltammograms, except for a major wave, which could be attributed by the authors to $\mathbf{C}_{\text {MIC }} \cdot \mathbf{H}^{+}$, the conjugate acid form of $\mathbf{C}_{\text {MIC. }}$ In our hands, $8 \mathrm{a}^{+}$and its derivatives were sensitive to moisture. In fact, the voltammetric signal of 
$\mathbf{8 a} \cdot \mathbf{H}$ was mistaken with the reduction wave of benzaldehyde at $E_{p}=-1.93 \mathrm{~V}$ and we could reproduce the previously proposed voltammograms for $\mathbf{8 a} \cdot \mathbf{H}$ with a mixture of hydrolysis products (benzaldehyde and $\mathrm{C}_{\text {MIC }} \cdot \mathrm{H}^{+}$, see Supporting Information). Special care was necessary to exclude moisture and to finally obtain satisfying reproducible cyclovoltammograms of $\mathbf{8 a}^{+}$, featuring two reversible reductions, at -1.0 and $-1.87 \mathrm{~V}$. Thus it turns out that, indeed, mesoionic carbenes are source of the powerful reducing agents in presence of aldehydes. However the transient electron donor is the enolate and not the enol form.

\section{Conclusion}

Early electrochemical studies for the determination of the reductive capability of enolates stemming from thiazolylidenes $\mathbf{C}_{\mathrm{NS}}$ organocatalysts and aldehydes relied on the in situ formation of these species in the electrochemical cell. We show that such approach involved an analytical bias due to the complexity of the mixture. We assessed this issue by studying isolable acyl azolium salts, the most oxidized form of the enolates. These compounds have been proposed as key intermediates in oxidative photo-redox catalytic cycles. Their synthesis is now possible with any NHC, including non-isolable thiazolylidenes $\mathbf{C}_{\mathrm{Ns}}$, by following our general synthetic strategy. It involves classical aqueous work-ups, suggesting that these salts are not as moisture sensitive as previously believed.

A broad library of salts has been prepared and the revised (or novel) electrochemical data offer an unprecedented panorama of the redox capability of enolates $\mathbf{A}^{-}$. They support a unified vision of mechanisms involving a SET from $\mathbf{A}^{-}$to the oxidative substrate. In absence of oxophilic Lewis acids and $\mathrm{H}$-bond donors, all $\mathrm{NHC}$, including biomimetic thiazolylidenes $\mathbf{C}_{\mathrm{Ns}}$ can generate strong reducing agents with potentials above $-1.7 \mathrm{~V}$ versus SCE. Several variants can be envisioned on a case-to-case basis. For instance, the possibility for non-radical pathways involving anionic intermediates from a second SET has already be mentioned for some processes. ${ }^{[3,4]}$ Furthermore, enolates stemming from most electron-rich $\mathrm{NHC}$, such as mesoionic $\mathbf{C}_{\text {MIC }}$, are strong enough to reduce aldehydes themselves. The reduction potential of these compounds (about $-1.9 \mathrm{~V}$ for benzaldehyde) constitutes a limit. Beyond this wall, a novel chemistry of ketyl radical anions can be envisioned, in line with Rehbein's intriguing proposal of possible off-path radical mechanisms for classical benzoin-type reactions. ${ }^{[23 a]}$

Breslow's mechanism had remained hypothetical for decades. The first observation and isolation of a thiazolylidene $\mathbf{C}_{\mathbf{N S}}$ was reported half a century later, ${ }^{[9,10]}$ and the corresponding Breslow intermediates a few years ago only. ${ }^{[11]}$ Establishing a better vision for the redox capability of the intermediates is another step towards a better comprehension of radical NHC-catalysis. Our next efforts will be directed towards a finer comprehension of the kinetics and thermodynamics in catalytic cycles. Meanwhile, we hope that future works and methodological results from the research community will enrich and challenge further these rough mechanistic proposals. 


\section{Acknowledgements}

This work was funded by the French National Agency for Research (ANR-20-CE070010). ETM contribution was a part of his program research, which is funded by the European Union under the Horizon 2020 Marie Skłodowska-Curie grant agreement No 892162. We acknowledge the CNRS and the University of Grenoble Alpes for a frictionless environment in the context of the Labex Arcane and CBH-EUR-GS (ANR17-EURE-0003). The authors thank Pr Cyrille Constentin for insightful discussions, the CECCIC centre of Grenoble for computer resources and the ICMG analytic platform, especially P. Girard, D. Gatineau, R. Sanahuges and N. Altounian for their outstanding service.

\section{References}

[1] Selected reviews on NHC-catalysis: (a) D. Enders, O. Niemeier, A. Henseler, Chem. Rev. 2007, 107, 5606-5655. (b) X. Bugaut, F. Glorius, Chem. Soc. Rev. 2012, 41, 3511-3522. (c) S. De Sarkar, A. Biswas, R. C. Samanta, A. Studer, Chem. Eur. J. 2013, 19, 4664-4678. (d) M. N. Hopkinson, C. Richter, M. Schedler, F. Glorius, Nature 2014, 510, 485-496. (e) D. M. Flanigan, F. Romanov-Michailidis, N. A. White, T. Rovis, Chem. Rev. 2015, 115, 9307-9387. (f) M. H. Wang, K. A. Scheidt, Angew. Chem. Int. Ed. 2016, 55, 14912-14922.

[2] J. Guin, S. De Sarkar, S. Grimme, A. Studer, Angew. Chem. Int. Ed. 2008, 47, 8727-8730.

[3] (a) N. A. White, T. Rovis, J. Am. Chem. Soc. 2014, 136, 14674-14677. (b) Y. Du, Y. Wang, X. Li, Y. Shao, G. Li, R. D. Webster, Y. R. Chi, Org. Lett. 2014, 16, 5678-5681.

[4] (a) N. A. White, T. Rovis, J. Am. Chem. Soc. 2015, 137, 10112-10115. (b) Y. Zhang, Y. Du, Z. Huang, J. Xu, X. Wu, Y. Wang, M. Wang, S. Yang, R. D. Webster, Y. R. Chi, J. Am. Chem. Soc. 2015, 137, 2416-2419. (c) B.-S. Li, Y. Wang, R. S. J. Proctor, Y. Zhang, R. D. Webster, S. Yang, B. Song, Y. R. Chi, Nature Commun. 2016, 7, 12933. (d) W. Yang, W. Hu, X. Dong, X. Li, J. Sun, Angew. Chem. Int. Ed. 2016, 55, 15783-15786. (e) Y. Wang, X. Wu, Y. R. Chi, Chem. Commun 2017, 53, 11952-11955. (f) Y. Wang, Y. Du, X. huang, X. Wu, Y. Zhang, S. Yang, Y. R. Chi, Org. Lett. 2017, 19, 632-635. (g) X. Wu, Y. Zhang, Y. Wang, J. Ke, M. Jeret, R. N. Reddi, S. Yang, B.A. Song, Y. R. Chi, Angew. Chem. Int. Ed. 2017, 56, 2942-2946. (h) X.-Y. Cheng, K.-Q. Chen, D. Q. Sun, S. Ye, Chem. Sci. 2017, 8, 1936-1941. (i) I. Kim, H. Im, H. Lee, S. Hong, Chem. Sci. 2020, 11, 3192-3197. (j) J.-L. Li, Y.-Q. Liu, W.-L. Zou, R. Zeng, X. Zhang, Y. Liu, B. Han, Y. He, H.-J. Leng, Q.-Z. Li, Angew. Chem. Int. Ed. 2020, 59, 1863-1870. (k) B. Zhang, Q. Peng, D. Guo, J. Wang, Org. Lett. 2020, 22, 443-447. (I) Z. Li, M. Huang, X. Zhang, J. Chen, Y. Huang, ACS Catal. 2021, 11, 10123-10130. (m) T. Ishii, K. Nagao, H. Ohmiya, Tetrahedron 2021, (pre-proof) https://doi.org/ 10.1016/j.tet.2021.132212.

[5] (a) T. Ishii, Y. Kakeno, K. Nagao, H. Ohmiya, J. Am. Chem. Soc. 2019, 141, 3854-3858. (b) Y. Kakeno, M. Kusakabe, K. Nagao, H. Ohmiya, ACS Catal. 2020, 10, 8524-8529

[6] (a) Y. Gao, Y. Quan, Z. Li, L. Gao, Z. Zhang, X. Zou, R. Yan, Y. Qu, K. Guo, Org. Lett. 2021, 23, 183-189. (b) L. Chen, S. Jin, J. Gao, T. Liu, Y. Shao, J. Feng, K. Wang, T. Lu, D. Du, Org. Lett. 2021, 23, 394-399. (c) H. B. Yang, D.-H. Wan, Org. Lett. 2021, 23, 1049-1053.

[7] Selected reviews and highlights: (a) K. Zhao, D. Enders, Angew. Chem. Int. Ed. 2017, 56, 37543756. (b) R. Song, Y. R. Chi, Angew.Chem. Int. Ed. 2019, 58, 8628-8630. (c) T. Ishii, K. Nagao, H. Ohmiya, Chem. Sci. 2020, 11, 5630-5636.

[8] For NHC catalyzed photoredox transformation of carbonyl derivatives, see : (a) D. A. DiRocco, T. Rovis , J. Am. Chem. Soc., 2012, 134 , 8094-8097. (b) J. Liu, X.-N. Xing, L.-Q. LuW.-J. Xiao, Chem. Sci. 2020, 11, 10605-10613. (c) Q.-Y. Meng, N. Döben and A. Studer, Angew. Chem. Int. Ed. 2020, 59, 19956-19960. (d) M. S. Liu, W. Shu, ACS Catal. 2020, 10, 12960-12966. (e) A. V. Davies, K. P. Fitzpatrick, R. C. Betori, K.A Scheidt, Angew. Chem. Int. Ed. 2020, 59, 9143-9148. 
(f) S.-C. Ren, W.-X. Lv, X. Yang, J.-L. Yan, J. Xu, F.-X. Wang, L. Hao H. Chai, Z. Jin, Y. R. Chi, ACS Catal. 2021, 11, 2925-2934. (g) M. S. Liu, L. Min, B.-H. Chen, W. Shu, ACS Catal. 2021, 11, 9715-9721. (h) Q.-Y. Meng, L. Lezius, A. Studer, Nature Commun. 2021, 12, 2068.

[9] R. Breslow, J. Am. Chem. Soc. 1958, 80, 3719-3726.

[10] For a recent review, see: M. Pareek, Y. Reddi, Chem. Sci. 2021, 12, 7973-7992.

[11] For the quest for direct observation of Breslow intermediates, see: (a) D. Meyer, P. Neumann, E. Koers, H. Sjuts, S. Lüdtke, G. M. Sheldrick, R. Ficner, K. Tittmann, Proc. Natl. Acad. Sc. USA 2012, 109, 10867-10872. (b) A. Berkessel, S. Elfert, V. R. Yatham, J.-M. Neudörfl, N. E. Schlörer, J. H. Teles, Angew. Chem. Int. Ed. 2012, 51, 12370-12374. (c) A. Berkessel, V. R. Yatham, S. Elfert, J.-M. Neudörfl, Angew. Chem. Int. Ed. 2013, 52, 11158-11162. (d) M. Paul, P. Sudkaow, A. Wessels, N. E. Schlörer, J.-M. Neudörfl, A. Berkessel, Angew. Chem. Int. Ed. 2018, 57, 83108315. (e) M. Paul, J.-M. Neudörfl, A. Berkessel, Angew. Chem. Int. Ed. 2019, 58, 10596-10600. (f) M. Paul, K. Peckelsen, T. Thomulka, J. Martens, G. Berden, J. Oomens, J.-M. Neudörfl, M. Breugst, A. J. H. M. Meijer, M. Schäfer, A. Berkessel, Chem. Eur. J. 2021, 27, 2662-2669.

[12] V. Regnier, E. A. Romero, F. Molton, R. Jazzar, G. Bertrand, D. Martin, J. Am. Chem. Soc. 2019, 141, 1109-1117.

[13] (a) I. Nakanishi, S. Itoh, T. Suenobu, S. Fukuzumi, Chem. Commun. 1997, 1927-1928. (b) I. Nakanishi, S. Itoh, T. Suenobu, S. Fukuzumi, Angew. Chem. Int. Ed. 1998, 37, 992-994. (c) I. Nakanishi, S. Itoh, S. Fukuzumi, Chem. Eur. J. 1999, 5, 2810-2818.

[14] For clarity, all potentials are given versus the standard saturated calomel electrode (SCE). We corrected values versus $\mathrm{Fc} / \mathrm{Fc}^{+}$, which is an other common reference, with $0.38 \mathrm{~V}$ versus SCE in acetonitrile, see: V. V. Pavlishchuk, A. W. Addison, Inorganica Chimica Acta 2000, 298, 97-102.

[15] K. Okada, K. Okamoto, M. Oda, J. Am. Chem. Soc. 1988, 110, 8736-8738.

[16] X.-Y. Yu, Q.-Q. Zhao, J. Chen, W.-J. Xiao, J.-R. Chen, Acc. Chem. Res. 2020, 53, 1066-1083.

[17] Y. Matsuki, N. Ohnishi, Y. Kakeno, S. Takemoto, T. Ishii, K. Nagao, H. Ohmiya, Nature Commun. 2021, 12, 3848.

[18] W. Liu, A. Vianna, Z. Zhang, S. Huang, L. Huang, M. Melaimi, G. Bertrand, X. Yan, Chem Catal. 2021, 1, 126-206.

[19] (a) H. G. Roth, N. A. Romero, D. A. Nicewicz, Synlett 2016, 27, 714-723. (b) L. Pause, M. Robert, J.-M. Savéant, J. Am. Chem. Soc. 1999, 121, 7158-7159.

[20] (a) J. K. Mahoney, D. Martin, C. R. Moore, A. L. Rheingold, G. Bertrand, J. Am. Chem. Soc. 2013, 135, 18766-18769. (b) J. K. Mahoney, D. Martin, F. Thomas, C. R. Moore, A. L. Rheingold, G. Bertrand, J. Am. Chem. Soc. 2015, 137, 7519-7525. (c) C. L. Deardorff, E. R. Sikma, C. P. Rhodes, T. W. Hudnall, Chem. Commun. 2016, 52, 9024-9027. (d) J. K. Mahoney, R. Jazzar, G. Royal, D. Martin, G. Bertrand, Chem. Eur. J. 2017, 23, 6206-6212. (e) K. Kato, A. Osuka, Angew. Chem. Int. Ed. 2019, 58, 8978-8986. (f) Y. Kim, E. Lee, Chem. Eur. J. 2018, 24, 19110-19121.

[21] (a) A. J. III Arduengo, J. R. Goerlich, W. J. Marshall, Liebigs Ann./Recl. 1997, 365-374. (b) I. Piel, M. D. Pawelczyk, K. Hirano, R. Fröhlich, F. Glorius, Eur. J. Org. Chem. 2011, 5475-5484.

[22] P. Lassalas, F. Marsais, C. Hoarau, Synlett 2013, 24, 2233-2240.

[23] (a) J. Rehbein, S.M. Ruser, J. Phan, Chem. Sci. 2015, 6, 6013-6018. (b) H. Leopold, A. Tronnier, G. Wagenblast, I. Munster, T. Strassner, Organometallics 2016, 35, 959-971.

[24] D. Hesek, M. Lee, B. C. Noll, J. F. Fisher, S.Mobashery, J. Org. Chem. 2009, 74, 2567-2570.

[25] (a) A. Beillard, X. Bantreil, T.-X. Métro, J. Martinez, F. Lamaty, Dalton Trans. 2016, 45, 1785917866. (b) S. S. Sohn, J. W. Bode, Org. Lett. 2005, 7, 3873-3876.

[26] J. Bouffard, B. K. Keitz, R. Tonner, G. Guisado-Barrios, G. Frenking, R. H. Grubbs, G. Bertrand, Organometallics 2011, 30, 2617-2627.

[27] Experimental values for isotropic hyperfine constants were extracted from EPR spectra by fitting with the EasySpin simulation package: S. Stoll, A. Schweiger, J. Magn. Reson. 2006, 178, 42-55.

[28] Calculations were performed with the Gaussian suite of programs: Gaussian 16, Revision B.01, M. J. Frisch, G. W. Trucks, H. B. Schlegel, G. E. Scuseria, M. A. Robb, J. R. Cheeseman, et al., Gaussian, Inc., Wallingford CT, 2016. See Supporting Information for complete citation

[29] For the electrochemical study of an O-methylated model, see: G. Barletta, A. C. Chung, C. B. Rios, F. Jordan, J. M. Schlegel, J. Am. Chem. Soc. 1990, 112, 8144-8149. 
[30] For a related electrochemical study, see: M. Oelgemöller, A. Haeuseler, M. Schmittel, A. G. Griesbeck, J. Lex, Y. Inoue, J. Chem. Soc., Perkin Trans. 2 2002, 676-686.

[31] C. C. Chiu, K. Pan, F. Jordan, J. Am. Chem. Soc. 1995, 117, 7027-7028.

[32] For examples and discussion, see: (a) J. Broggi, T. Terme, P. Vanelle, Angew. Chem., Int. Ed. 2014, 53, 384-413. (b) M. P. Drapeau, I. Fabre, L. Grimaud, I. Ciofini, T. Ollevier, M. Taillefer, Angew. Chem. Int. Ed. 2015, 54,10587-10591. (c) G. B. Panetti, P. J. Carroll, M. R. Gau, B. C. Manor, E. J. Schelter, P. J. Walsh, Chem. Sci. 2021, 12, 4405-4410. 